\title{
CORPO SURDO E SUAS SINGULARIDADES
}

Aline Rodrigues ${ }^{1}$

Angélica Vier Munhoz ${ }^{2}$ Morgana Domênica Hattge ${ }^{3}$

\section{Resumo}

O presente artigo refere-se a um recorte da dissertação de mestrado realizada no Centro Universitário Univates no período de julho de 2013 a julho de 2015. Em meio a teorizações de filósofos da diferença, entre eles Deleuze e Barthes, toma-se o seguinte problema de pesquisa: Como um corpo surdo é pungido por outras vias que não a representação? Tal problema desdobra-se nos seguintes objetivos: compreender os modos pelos quais alguns corpos surdos se singularizam e como potencializam sua vida; carto(foto)grafar os afetos produzidos pelo corpo surdo em encontros com a fotografia. Estas carto(foto)grafias foram realizadas em momentos distintos, com três sujeitos surdos nas cidades de Lajeado/RS e Estrela/RS, a partir de trajetos percorridos com o uso da câmera fotográfica. $\mathrm{O}$ encontro com a obra "Caminhando", de Lygia Clark (1964) serviu para que o percurso fosse pensado enquanto obra que se realiza no ato. Por vezes, um corpo inacabado, em movimento de constante recusa à fixação. Em muitas outras, apenas um corpo capturado por linhas estratificadas. Ao finalizar a pesquisa, percebe-se que a entrega do corpo é sempre algo difícil, de modo que fixa-se mais na objetividade e brevidade, do que naquilo que um corpo é capaz de produzir enquanto singularidade.

\footnotetext{
1 Pedagoga. Bolsista CAPES do Mestrado em Ensino pelo Centro Universitário Univates. Rua Avelino Tallini, 171, Bairro Universitário-Lajeado/RS - Brasil. aliner@ universo.univates.br

${ }^{2}$ Doutora em Educação; Docente do Centro de Ciências Humanas e Sociais e do Programa de Pós-Graduação Mestrado em Ensino - Centro Universitário Univates. Rua Avelino Tallini, 171, Bairro Universitário-Lajeado/RS - Brasil. angelicavmunhoz@ gmail.com

${ }^{3}$ Doutora em Educação; Docente e Coordenadora do Curso de Pedagogia - Centro Universitário Univates. Rua Avelino Tallini, 171, Bairro Universitário-Lajeado/RS - Brasil. morganahdomenica@gmail.com
} 
Palavras-chave: Corpo surdo; Punctum; Carto(foto)grafia

\section{INTRODUÇÃO}

Esta escrita traz parte da dissertação de Mestrado em Ensino realizado no Centro Universitário UNIVATES, durante o período de julho de 2013 a julho de 2015. Em virtude de estar em contato com surdos em algumas disciplinas dos cursos de graduação do Centro Universitário Univates, muitas inquietações e questionamentos começaram a surgir e instigaram a realização desse estudo.

Um cenário habitado por sujeitos surdos, que através das suas singularidades tentavam fazer emergir suas diferenças, em um espaço que, algumas vezes, tentava enquadrá-los como sujeitos anormais. Neste estudo, buscamos pensar sujeitos surdos desvinculados da (a)normalidade, mas muito mais olhá-los pelo prisma da potência. Sujeitos e corpos surdos que se potencializam em seus afetos e que através deles, desenham suas vidas.

Neste propósito, filósofos da diferença, dentre eles Deleuze e Barthes, os quais contribuíram para pensar o seguinte problema de pesquisa: como um corpo surdo é pungido por outras vias que não a da representação? A partir de conexões em torno desta questão, tomamos a carto(foto)grafia como método da investigação tendo em vista registrar afetos por meio de fotografias. Tais carto(foto)grafias foram realizadas com três surdas adultas, nas cidades de Lajeado/RS e Estrela/RS.

O artigo compõe-se de um primeiro capítulo que aborda as representações do corpo surdo, trazendo alguns trilhos delineados historicamente. Em um segundo capítulo, busca-se pensar o corpo surdo enquanto singularidade. No terceiro capítulo, o objetivo é tecer o corpo surdo com a carto(foto)grafia, enquanto método escolhido. A aproximação com a obra "Caminhando", de Lygia Clark (1964) serviu para que tal percurso fosse pensado enquanto obra que se realiza no ato. No quarto, são tramadas algumas intensidades, mostrando as experiências dos encontros com os caminhantes e ao final, conclui-se apontando os desencontros, os descaminhos, as encruzilhadas e as suspeitas encontradas no decorrer do processo da dissertação. 


\section{DOS OLHARES HISTÓRICOS}

Traça-se, inicialmente, um resgate histórico, social e cultural que marcou o corpo surdo, entre discursos médicos, sociais e educacionais. Algumas representações culturais tecem a história dos surdos e elas são aqui mapeadas, problematizando os discursos que produzem as identidades dos corpos surdos.

Nas sociedades antigas ocorriam castigos aos surdos decorrentes da sua condição de não ouvintes. Essa condição os colocava no lugar de não normais ou não perfeitos. Sobre esta prática, Lunardi (2004, p. 23) diz que "tanto loucos, doentes mentais, criminosos e populações marginais quanto qualquer outro "anormal" deveriam ser isolados (...)".

Até o século XVI, o surdo era classificado e identificado como marginalizado e anormal, geralmente sendo preso e escondido em suas casas pela família, que se envergonhava de mostrar para a sociedade que tinha uma pessoa surda em seu meio. Eles eram vistos pelas famílias como um castigo de Deus e para a sociedade eram improdutivos e por isso inúteis. Neste sentido, Thoma (2006, p. 11) afirma que “(...) os filhos defeituosos de tais famílias eram retirados da visão pública pela vergonha que causavam, pois eram considerados resultados das depravações ou pecados cometidos por seus pais”.

O tempo foi passando e no século XVI, ou no período moderno, na Espanha, surgem os primeiros educadores de surdos. O monge Pedro Ponce de Leão (1520-1584) inicia a educação dos surdos através do uso da Língua de Sinais e do alfabeto manual, além de fundar uma escola de professores surdos. Nas palavras de Thoma (2006, p. 11), “(...) D. Pedro Ponce de Leão, na Espanha, inicia um trabalho voltado a desenvolver a fala (oral) nos então denominados surdos-mudos". Ainda de acordo com Thoma (2006), com estas iniciativas do monge, os trabalhos foram ganhando força, tanto que o século XVIII ficou marcado como o período mais fértil da educação de surdos, devido ao aumento do número de escolas e do ensino da Língua de Sinais.

Essas práticas sobre a língua de sinais foram se disseminando também na Inglaterra, Portugal e França, tendo como destaque em 1750 o abade francês Michel de L'Epée, que criou os Sinais Metódicos. O método criado por ele foi uma combinação de língua de sinais com gramática sinalizada francesa, além de definir a mímica como linguagem materna e concluir que os gestos são os meios de comunicação dos surdos. Este educador transformou sua casa em escola pública e acreditava que todos os surdos deveriam ter acesso à educação. 
Pode-se perceber aqui um discurso de salvação religiosa, com um caráter de caridade.

De acordo com Thoma (2006), L'Epée iniciou o trabalho de instrução formal com duas surdas, a partir da Língua de Sinais que era falada pelas ruas de Paris. Sua instrução foi baseada na datilologia/alfabeto manual e sinais criados, e obteve grande êxito, e a partir dessa época a metodologia por ele desenvolvida tornou-se conhecida e respeitada, assumida pelo então Instituto de Surdos e Mudos (atual Instituto Nacional de Jovens Surdos), em Paris, como o caminho correto para a educação dos seus alunos.

Também por volta de 1750 a Alemanha e os Estados Unidos realizavam seus estudos e em 1754 o alemão Samuel Heinick trabalhou a filosofia oralista. Em 1815, Thomas Hopkins Gallaudet e Laurent Clerc adaptam os estudos da língua de sinais francesa para o inglês e em 1864 é fundada a primeira universidade para surdos nos Estados Unidos. Neste período houve uma elevação no grau de escolarização dos surdos, que podiam aprender com facilidade as disciplinas ministradas em língua de sinais.

Porém, o oralismo passa a ter força e surgem oposições à língua de sinais. No ano de 1880 em Milão, na Itália, ocorreu o II Congresso Mundial dos Surdos, que passou a considerar que o uso simultâneo da fala e dos gestos mímicos tinha a desvantagem de impedir o desenvolvimento da fala da leitura labial e da precisão das ideias. E declara que o método oral puro deveria ser preferido de forma definitiva e oficial. Das 164 representantes presentes, apenas cinco dos EUA não votam em favor do oralismo. Assim, a língua de sinais foi proibida, o que provocou tensões na educação de surdos. Sobre as tentativas de fazer as pessoas surdas falarem, Lopes (2004, p. 41) diz que “[...] sempre diferentes dos outros e de si mesmas, nessa lógica ouvintista e normalizadora, as pessoas surdas deviam (...) aprender a falar, pois estariam mais próximas de um lugar de normalidade tido e inventado como sendo o referente."

Neste momento da história, a cultura surda foi vista como déficits sensoriais, que deveriam ser corrigidos através do treino da fala, sendo esta indispensável quando se trata de aceitação social. Assim, a surdez é vista, nesse período, como uma patologia e por isso precisa de tratamento médico. Neste momento, surgem as pedagogias corretivas e na escola os surdos deveriam sentar sobre as mãos, para que não tivessem nenhuma possibilidade de usar os sinais. Sentar sobre as mãos era uma das formas de impedir o uso de sinais, além de outras alternativas utilizadas, como por exemplo amarrar as mãos e outras punições aos surdos que sinalizassem. 
Apesar de tal mudança, os códigos não chegaram a ser eliminados, porém simplesmente foram conduzidos à marginalização. $\mathrm{O}$ atendimento aos surdos ficou voltado à filantropia e ao assistencialismo: os indivíduos eram entregues pelas famílias às instituições e aos asilos, em regime de internato. Neste sentido, trazemos as palavras de Gesser (2009, p. 67) afirmando que "o discurso médico tem muito mais força e prestígio do que o discurso da diversidade $[\ldots] "$.

No Brasil, percebe-se a convivência, mesmo que conflituosa, das três principais abordagens pedagógicas: oralismo, comunicação total e bilinguismo. A educação surda iniciou, no Brasil, durante o Segundo Império quando Dom Pedro II trouxe o professor surdo francês Eduard Huet. Em 1857 foi fundado o Instituto Nacional de Surdos-Mudos (atual Instituto Nacional de Educação dos Surdos - INES), localizado no Rio de Janeiro. De acordo com Thoma (2006, p. 12) "a educação dos surdos no Brasil foi fortemente influenciada por um professor surdo francês que veio ao país em 1857 a convite de D. Pedro II. Eduard Huet cria, nesse mesmo ano, o Instituto Nacional dos Surdos-Mudos (INSM) e começa suas atividades $[\ldots]$ "

O termo "Deficiência Auditiva" começa a surgir em 1950, com o crescente poder do método oralista francês que cresce em todo o Brasil, sob a responsabilidade da Prof ${ }^{a}$. Alpia Couto, que, dentro do Centro Nacional de Educação Especial, realiza projetos em torno desta nomenclatura. $\mathrm{O}$ desconhecimento e a falta de convivência com os surdos provocam prejuízos na cultura da comunidade surda, o empobrecimento da Língua de Sinais e a falta de acesso às informações sociais. As questões da Educação Especial se tornam assim apenas vinculadas a interesses político-econômicos.

Chega ao Brasil, em 1975, a Comunicação Total e dois anos após é criado, no Rio de Janeiro, a Federação Nacional de Educação e Integração dos Deficientes Auditivos (FENEIDA), com diretoria de ouvintes. No entanto, tanto o Oralismo quanto a Comunicação Total procuram ajustar os surdos à ordem padrão vigente: sujeitos ouvintes.

Por volta de 1980 inicia-se no Brasil o bilinguismo e em seguida são iniciadas pesquisas sistematizadas sobre a Língua de Sinais. Em 1983 é criada no país a Comissão de Luta pelos Direitos dos Surdos e três anos depois o Centro SUVAG (Sistema Universal Verbotonal de Audição Guberina, de Pernambuco-Brasil) ${ }^{4}$ faz sua opção metodológica pelo

\footnotetext{
${ }^{4}$ Trata-se de um método oral multissensorial, pois visa à habilitação do indivíduo para a fala e à constante reabilitação da audição deficiente. Este método, criado por Peter Guberina, na Iugoslávia, pode ser e é aplicado em indivíduos surdos de todas as idades, desde a estimulação precoce $(0$ ano $)$ até a estimulação para a
} 
Bilinguismo, tornando-se o primeiro lugar no Brasil em que efetivamente esta orientação passou a ser praticada. Em 16 de maio de 1987 é criada a Federação Nacional de Educação e Integração dos Surdos (FENEIS), sob a direção de surdos. Sobre o bilinguismo, Pereira e Marostega (2002, texto digital) afirmam que "[...] primeiramente, o Surdo deve adquirir a (LS) e, como segunda língua, a língua do país a que pertence. A abordagem bilíngüe coloca em evidência a (LS), porque esta é a forma espontânea de comunicação no mundo das pessoas Surdas."

A LIBRAS (Língua Brasileira de Sinais) é reconhecida oficialmente pelo Governo do Estado de Minas Gerais, em 1991 (lei no 10.397 de 10/1/91). Em 1994 começa a ser exibido na TV Educativa o programa VEJO VOZES (out/94 a fev/95), usando LIBRAS. Em 1995 é criado por surdos no Rio de Janeiro o Comitê Pró-Oficialização da Língua de Sinais. Um ano após são iniciadas, no INES, em convênio com a Universidade do Estado do Rio de Janeiro (UERJ), pesquisas que envolvem a implantação da abordagem educacional com bilinguismo em turmas da pré-escola, sob a coordenação da linguista E. Fernandes.

No ano de 1998 a TELERJ (Telecomunicações do Estado do Rio de Janeiro), em parceria com a FENEIS, inauguraram a Central de atendimento ao surdo - através do número 1402, o surdo em seu TS (TeleSync - método de gravação de som), pode se comunicar com o ouvinte em telefone convencional. A educação de surdos vai se expandindo e em março de 1999 começam a ser instaladas em todo Brasil tele salas com o Telecurso 2000 legendado. Por volta do ano 2000 o Closed Caption, ou legenda oculta passa a ser utilizado e após três anos de funcionamento no Jornal Nacional ela é disponibilizada aos surdos também nos programas Fantástico, Bom Dia Brasil, Jornal Hoje, Jornal da Globo e programa do Jô. Também neste ano a TELERJ lança telefone celular para surdos com a opção de SMS. Em 2002 é promulgada a lei 10.436 em 24 de abril, reconhecendo a LIBRAS como meio legal de comunicação e expressão.

Com este reconhecimento, também começou a se pensar em incluir a LIBRAS na formação de professores, tanto em cursos voltados para os professores que atuam com alunos surdos, quanto em cursos voltados para os professores que ainda não atuam com os mesmos, visando assim uma preparação para os docentes de modo geral.

manutenção da linguagem em pessoas adultas que ensurdeceram e em pessoas com dupla ou múltiplas deficiências. O objetivo básico do método é treinar o cérebro para utilizar até mesmo uma mensagem acústica distorcida para a percepção da fala, aproveitando áreas mais sensitivas da audição. Disponível: $<$ http://suvagnarede.blogspot.com.br/2009/04/o-que-significa-suvag.html>. Acesso em: 06 abr. 2015. 
Permeando estes estudos, percebe-se que o sujeito surdo interage com o mundo a partir de uma experiência visual. Todas as suas construções mentais são mediadas pela sua língua materna: a língua de sinais. Assim, compartilhando uma língua comum, os surdos são reconhecidos como membros de uma comunidade singular.

No século XX é que começa, em alguns casos, a preocupação de "tirar o surdo do esconderijo". Ao ser visto como um indivíduo diferente com relação aos demais, passou-se a legislar algumas normas, como por exemplo, o reconhecimento da LIBRAS como sua primeira língua. Se por um lado todas essas medidas possibilitaram a inserção dos surdos em espaços antes não ocupados por eles, por outro lado, contribuíram para o aprisionamento do surdo em uma identidade.

Ressalta-se que algumas identidades foram historicamente atribuídas aos surdos, das quais advinham dispositivos que capturavam socialmente as vidas dos sujeitos, ou seja, a partir das nomenclaturas "recebidas" (e realmente "recebidas", uma vez que elas foram criadas por ouvintes) as regras do jogo iam sofrendo modificações. Desse modo o corpo surdo, enquanto categoria identitária, foi sendo constituído ao longo da história. Thoma (2006, p. 67) afirma que “[...] a alteridade surda é narrada e mostrada através de lentes "ouvintes" que capturam olhares dos que ouvem sobre os sujeitos surdos, sobre sua existência, sobre a necessária correção/normalização de seus corpos mutilados.”

Várias representações foram criadas aos surdos por ouvintes. Palavras, como mudo, deficiente, anormal, doente e outros, fizeram parte dessa construção. Nesses discursos, a falta da audição produz impactos na sociedade ouvinte, que passa a identificá-los com diferentes nomenclaturas negativas, por não possuírem a audição, que, para a vida "normal" em sociedade, são necessárias. Sobre esta questão, Lanna Júnior (2010, p. 14 e 15) afirma que "a busca por novas denominações reflete a intenção de rompimento com as premissas de menosvalia que até então embasavam a visão sobre a deficiência."

Importante destacar que embora delineia-se aqui alguns fatores históricos que permeiam marcas em torno dos surdos, esse não é o foco da referida pesquisa. Os descritos apenas servem como maneira de situar cultural e socialmente a escrita. Nos capítulos que seguem busca-se tramar um corpo surdo que tenta escapar a estas representações apresentadas, na tentativa de dar visibilidade às suas singularidades.

\section{UM CORPO DA SENSAÇÃO}


Busca-se pensar o corpo e seus devires. Na aproximação com filósofos da diferença, entre eles, Deleuze e Barthes traça-se um aporte teórico para problematizar este tema. Um corpo surdo, que na sua potência, é capaz de modificar os discursos de negação, pelos das sensações. Discursos que não estão dados, mas são cri ados, na ordem do vivido, do vivenciado, do experimentado, do sensível. Ao pensar neste corpo surdo tenta-se tecer linhas de um novelo emaranhado que está sempre em busca de fugir, de escapar, dos discursos que querem amarrá-lo à representação. Um corpo surdo como um novelo, que rola, ora abre, ora ata, encontra alguns nós em seu existir. O corpo está atrelado às nossas ações, mostra-nos que a vida pulsa e acontece, criando-se a cada encontro. Zourabichvili (2004, p. 61) diz que “(...) é na experiência que aprendemos a superioridade intensiva dos afetos - isto é: do encontro com o heterogêneo ou com o fora pelo qual toda a afectividade se vê abalada e redistribuída sobre as afeições comuns". É nos encontros intensivos, aqueles que lançam tudo para fora do previsível, nos afetos que provocam o corpo e o pensamento a pensar além do sensório-motor e da consciência, que nos agenciamos à vida.

Durante a pesquisa, busca-se mapear um corpo surdo, não para identificá-lo a um modelo ou cópia, mas que quer efetuar a sua potência. Vida mapeada pelo singular, pelo heterogêneo, não pela homogeneidade, categorias ou igualdade. Corpos que se movimentam, mãos que não param, sujeitos que experimentam a vida na sua singularidade. Corpos surdos que andam pelas ruas, pairando sobre olhares que procuram enquadrá-los, mas querem escapar às categorizações.

Um corpo que é força, que não busca uma forma, que cria, torce, se distorce em gestos, ruídos, acenos, expressões faciais, não nega, mas afirma sua singularidade. Assim, um corpo surdo não se aliena ao mundo, mas deseja desvincular-se da repetição do mesmo. Ele busca energia nas miudezas, nos acontecimentos, nos riscos que o vento traça no ar. Tal corpo possui características e singularidades específicas, que ao saltar aos olhos do outro passam a ser designadas como fora dos padrões. De que maneira abordá-lo? Tocá-lo? Chamá-lo? Entrar pela via visual, falar olhando para o corpo surdo, parando, usando as mãos e a expressão facial.

Um corpo talvez queira que você o pare, pois deseja uma outra velocidade, um estar presente com intensidade. Conversa? O que comunico? Há receitas? Parar e viver o instante. Andar conforme o ritmo da vida, o bailar do vento, o correr do rio. Ir além dos binarismos que 
distinguem indivíduos, tentando pensar um corpo surdo que é múltiplo, que se inventa e se reinventa durante todo tempo, simplesmente porque tem a potência de um corpo.

Para compreender o modo como o corpo institui-se como modelo, torna-se necessário recorrer a Platão e à ideia de representação. O método da divisão de Platão consiste em distinguir o puro e o impuro, o inteligível e o sensível, o autêntico e o inautêntico, o verdadeiro e o falso. Em tal distinção manifesta, Platão estabelece em um primeiro momento a dualidade modelo e cópia. Em uma segunda distinção, Platão cria dois tipos de imagens: a boa cópia e a má cópia. Segundo Machado (2013, p. 45):

A principal distinção, a "verdadeira" distinção, estabelecida por Platão é entre dois tipos de imagens, dois tipos de cópia: a boa cópia, a cópia bem fundada, o "ícone", que é uma imagem dotada de semelhança, e a má cópia, a cópia que implica uma perversão, o "simulacro-fantasma", que é uma imagem sem semelhança".

Dessa forma, opera-se com um corpo surdo em estado de simulacro, numa tentativa de fuga às noções de semelhança e identidade. Para Schöpke (2012, p. 23 - 24):

Segundo Deleuze, quando Platão condenava os simulacros, ele estava primeiramente condenando todo o qualquer estado de diferença livre, de distribuição nômade tudo aquilo que recusava, por sua existência, a noção de um modelo prévio. O simulacro contesta tanto a existência do original quanto da cópia. Ele é a instância que compreende, em si, uma diferença.

Neste sentido, a tentativa é de pensar as forças de um corpo surdo pelo olhar da diferença enquanto potencialização de suas singularidades e particularidades, deslocando-o do mesmo, da identidade. Um corpo surdo pensado não sob o prisma da diversidade, mas pelo viés da multiplicidade, pois "toda diversidade e toda mudança remetem a uma diferença que é sua razão suficiente”. (DELEUZE, 2006, p. 313). Dessa forma, trata-se de operar não por uma razão suficiente, mas por um corpo surdo atravessado por intensidades. Intensidades na diferença enquanto razão do sensível, diferença em si mesma, sem preocupação com corpos surdos semelhantes ou iguais. Uma intensidade diferencial que "designa catástrofes: sejam rupturas de continuidade na série das semelhanças, sejam falhas intransponíveis entre estruturas análogas" (DELEUZE, 2006, p. 65).

A diferença em si não tem relação, nem comparação com o outro, é um exercício de abandonar a identidade, para tornar-se um devir-outro. Ao acreditar na potente força da diferença em si e em tentativas de escapar ao idêntico, toma-se o corpo surdo de modo sensível, uma vez que "a razão do sensível, a condição daquilo que aparece não é o espaço e o 
tempo, mas o Desigual em si, a disparação tal como é compreendida e determinada na diferença de intensidade, na intensidade como diferença.” (DELEUZE, 2006, p. 314). Contudo, algumas vezes torna-se necessário balançar a indagação de Clark (2013, p. 354): "Sinto-me sem categoria, onde é meu lugar no mundo?"

Um corpo pode ser assim pensado enquanto potencialidade de vida: visível- invisível. Ora mostra a sua potência, ora a esconde. Provocações apenas. Linhas. Entrelinhas. Ligação. Um corpo surdo artista que não deseja o quadro rapidamente pronto, acabado, mas que apara cada aresta da vida sem pressa, como um pintor que se entrega à criação. Um traço num dia, um rabisco no outro. Pinceladas imanentes à vida, às possibilidades, aos movimentos.

Entre as diferentes maneiras de olhar o tempo presente, toma-se as ideias de Lopes, quando afirma que é preciso uma "liberdade para mudar sua condição. Tem também mobilidade para sair das posições, identidades e funções que ocupam” (LOPES, 2009, p. 125).

\section{ATRAVESSAMENTOS METODOLÓGICOS}

Cartografando. Fotografando. Caminhando. Uma lembrança à Lygia Clark e sua obra Caminhando. A obra Caminhando foi produzida pela artista Lygia Clark em 1964. Consiste em pegar uma tira de papel e juntar as pontas para formar um círculo. Antes, é preciso girar uma delas e a colar do lado contrário, de modo que esse círculo se transforme numa fita de Moebius, da qual não se pode dizer onde é o dentro e onde é o fora. Pega-se uma tesoura, faz um furo no papel e começa a cortar no sentido do comprimento, circulando por toda a extensão da tira, fazendo uma volta completa. Só não pode dividi-la em duas. Quando estiver próximo do início, decide-se se continua pela direita ou pela esquerda do corte que acabou de fazer.

Busca-se relacionar a obra Caminhando com a experiência que foi descrita na dissertação, como obra que se realiza no ato, uma caminhada que tem várias direções, na qual não há espaços para voltar atrás. As marcas, as escolhas ficam registradas através das lentes da câmera. Mesmo na técnica utilizada pela artista, querendo reverter uma escolha, colando as tiras ou buscando outros recortes, a marca permanecerá, como uma cicatriz do gesto, não esquecendo o que passou. Com a obra Caminhando, Lygia Clark tenta transformar o material num gesto, livrando-o das formas estabelecidas, escapando os moldes e modificando assim, as estruturadas, singularizando-as. Clark (1964) diz que sua obra é apenas uma potencialidade. O 
sujeito e a ação formarão uma realidade, em uma mistura entre sujeito-objeto, por isso uma fusão, um corpo-a-corpo. As diferentes construções surgirão das escolhas em meio a esta fusão. Entrelaçamentos em transição, experiência por onde se percorre, não sabendo se pela direita, pela esquerda, pela frente, por trás, apenas segue-se.

No entremeio de tal fusão, encontra-se os corpos surdos, os quais passam a ser chamados de caminhantes. A escolha dessa denominação deve-se por um lado, pelo contágio com a obra Caminhando de Lígia Clark; por outro, porque o contato com os corpos surdos foi realizado através de alguns percursos realizados a pé, ou seja, caminhando.

Três foram os caminhantes desta pesquisa, todas mulheres, surdas, da faixa etária entre 30 a 39 anos de idade, moradores de Lajeado/RS e Estrela/RS. Mulheres adultas com as quais a pesquisadora teve contato em alguns momentos da vida. As caminhantes, junto com a pesquisadora, percorreram trajetos, ora escolhidos por elas, ora combinados com o grupo. Dessa forma, alguns percursos foram realizados somente com uma caminhante, outros com as três juntas. Durante os encontros, todas as comunicações ocorreram em LIBRAS, tanto entre pesquisadora e caminhantes, quanto entre as caminhantes.

Todos os convites para os encontros foram realizados via e-mail. Quando o contato era inicial, uma explicação breve do trabalho foi dada, esclarecendo que estava sendo realizada tal pesquisa e questionando se poderíamos nos encontrar para conversar mais. No momento do encontro, explicava-se sobre a experiência fotográfica que seria proposta como forma de registro do que afetava, um momento de fruição da vida.

Nenhuma proposta anterior provocando um olhar sensível foi realizada, pensando-se numa relação com o instante, não de maneira planejada ou conduzida. Também pessoalmente comentava sobre o interesse pelas descontinuidades. Os três primeiros encontros individuais tiveram a duração aproximada de 45 minutos, e o último, o coletivo, durou aproximadamente uma hora e 15 minutos, talvez pelas trocas terem sido realizadas com mais pessoas.

Foram registradas as sensações experimentadas a cada encontro, utilizando o diário de campo, conversas, fotografias e filmagens como ferramentas. Sobre a escolha do diário de campo, o mesmo contém notas e experiências das vivências, não com o propósito de relatar tudo, mas uma escrita que traz a intensidade dos acontecimentos, com uma linguagem literária e não técnica ou científica. Desta forma, o diário de campo nesta pesquisa não configura-se como um relatório de cada passo da caminhada realizada com cada caminhante, mas como um instrumento que foi sendo produzido concomitante com as intensidades dos encontros. 
A partir dos princípios da cartografia, escolhe-se a carto(foto)grafia como ferramenta metodológica de pesquisa, por possibilitar uma abertura aos encontros, por se tratar de uma proposta que permite que sensações sejam fruídas; experiências, trocadas e vidas, potencializadas e registradas. Propõe-se assim mapear os encontros dos caminhantes com a fotografia, acompanhando os processos e estando-se sensível aos acontecimentos que pungem o olhar.

A carto(foto)grafia surge da composição entre as palavras "cartografia" e "fotografia" e é nesse exercício que se é lançado: realizar uma pesquisa carto(foto)grafando os encontros, os punctuns aos quais os caminhantes vão sendo afetados durante o caminhar.

Barthes (1984) diz que o punctum é sempre uma entrega, pois o que punge é sempre algo que diz do sujeito. Aliado ao punctum na fotografia, Barthes (1984) também traz o conceito de studium, não sendo um excludente do outro, mas conceitos que estão se cruzando. Para ele, o studium é o que faz com que uma fotografia seja reconhecida, podendo ser a cultura, o local ou qualquer outro motivo que faz com que o sujeito goste ou não goste da imagem. Sobre o studium, Barthes (1984, p.45) diz que "não quer dizer, pelo menos de imediato, "estudo", mas a aplicação a uma coisa, o gosto por alguém, uma espécie de investimento geral, ardoroso, é verdade, mas sem acuidade particular".

Em torno de punctuns, a carto(foto)grafia foi operada como encontros imprevistos, impensados, sem demarcação de pontos de chegada, mas possibilidades de caminhar construindo, trocando, potencializando os corpos surdos durante as experimentações.

A fotografia tem um modo próprio de quem segura a câmera, ou de quem fotografa. Um olhar. Multiplicidade, mas ao mesmo tempo um foco. Olhar o que afeta, afeto para onde dispara o flash. Criação de provocações que indagam sobre a imagem fotografada. Fotografar singularidades? Formas de o corpo surdo experimentar, ver e narrar o que está em meio a sua vida. Sensibilidades na contemporaneidade. Concretizar as experiências, registrar, pegar, captar o sensível. Alguns excertos das caminhadas realizadas com as caminhantes:

Inicia-se uma caminhada, com os pés descompassados, sem saber para onde ir. Lispector (1980, p. 69) diz "as horas passam como muitos anos, e os anos se passam realmente, as borboletas cheias de grandes asas (...)". Em meio aos trajetos percorridos, destaca-se alguns fragmentos. Fotografar este ou aquele objeto, esta ou aquela pessoa. A fotografia é sempre singular, única para cada um que vê. Os caminhantes que registraram os punctuns foram identificados pelos codinomes A, B, C. 
Olhávamos para um lado, olhávamos para o outro lado. 0 ambiente por onde caminhávamos era um tanto familiar, corriqueiro. Máquina fotográfica na mão. Em um primeiro momento, o desejo de sair junto na foto, querendo deitar-se no gramado, desejando senti-lo na carne. Num segundo movimento, fotografias da natureza, sem pessoas focadas. "Era uma coisa. Quieta, bonita, sozinha. Encurralada naquele canto, sem mais, nem menos" (LISPECTOR, 1980, p. 128). A natureza que a tocou foi a mesma que nos tocou. (Diário de bordo da pesquisadora)

A caminhante $C$ também comentou sobre a força que vê na grama, um emaranhado na terra, um entrelaçar vibrátil. Neste sentido, Lispector (1973, p. 44) diz: "Gosto é das paisagens de terra esturricada e seca, com árvores contorcidas e montanhas feitas de rocha e com uma luz alvar e suspensa. Ali, sim, é que a beleza recôndita está". Da mesma forma que a grama, o sol registrado pela fotografia também pungiu o olhar da caminhante $C$, que disse sentir a vida recheada de energia quando ele está presente no dia, iluminando os pensamentos, permitindo que as "(...) visceras torturadas [...] guiam" (LISPECTOR, 1973, p. 32) um corpo. (Diário de bordo da pesquisadora)

Uma vista da casa. Uma morada. Um aconchego. Uma vista que se modifica a todo 0 instante. Galhos caem, flores secam. Espaço que se modifica com o som que balança as folhas e o vento que sopra entre as nuvens. Um retrato, que assim como um corpo não deseja ser moldado, nem repetido, mas transposto, experimentado. Uma fotografia de um instante. Uma fotografia como singular, conforme Lispector (1999, p.70) diz em sua poética, que fotografar é "pegar o vivo e tirar o seu imóvel retrato e olhar-se no retrato e pensar que o flagrante deixou uma prova, a desse retrato já morto (...)". A câmera fotográfica singularizou o instante, que pelas derivas e afecções foi composto. (Diário de bordo da pesquisadora em encontro com a caminhante C)

Dessa forma, o percurso inventa o seu trilhar na medida em que se encontra a campo com seus caminhantes. Implicada em tal procedimento da pesquisa, não há uma neutralidade do pesquisador, nem distância dos caminhantes, mistura-se a eles.

\section{DOS ENCONTROS}

Nesta pesquisa foram realizadas tentativas de suspender o tempo chronos nos percursos que foram tecidos com os caminhantes. Para percorrer este processo de pesquisa e acompanhar a relação dos caminhantes com a fotografia, tornou-se necessário passar pela experiência, caminhando com os caminhantes, constituindo esse próprio caminho no decorrer das sensações. Por isso, não era possível estar do lado 'de fora' dos encontros, mas sim neles imersa. Sobre isso, Costa (2009) fala de uma mistura entre o cartógrafo e seus parceiros de 
caminhada, onde fluxos e saberes são vacilantes. A mistura, neste sentido, resiste aos congelamentos destes fluxos.

A intenção carto(foto)gráfica era combinar encontros com os caminhantes em lugares diversificados, de acordo com suas escolhas e caminhar com eles, fruindo os lugares, conversando e registrando, por meio da câmera fotográfica, o que pungia seus sentidos, afetando suas singularidades. Nestas caminhadas procura-se viver de acordo com o que punge os sentidos, pois a carto(foto)grafia foi tecida por um acompanhamento de processo que foram se construindo e ela exigiu uma disposição dos sujeitos para os afetos.

Ao pensar o trabalho empírico de forma carto(foto)gráfica, percebe-se o quanto é necessário e, ao mesmo tempo, difícil realizar um despojamento de conceitos até então estabelecidos como verdadeiros. Surge uma necessidade de vivenciar, experienciar, deixar as situações acontecerem para nelas sentir o que irá afetar. Kastrup (2009) diz que as informações, os saberes e as expectativas devem ser "deixados na porta de entrada, e o cartógrafo deve centrar-se, sobretudo, numa atenção sensível, para que possa, enfim, encontrar o que não conhecia, embora já estivesse ali, como virtualidade” (p. 48 e 49). Assim, a ideia foi ir a campo desnuda e lá encontrar algo que fisgasse.

$\mathrm{Na}$ carto(foto)grafia realizada, os critérios de verdade ou juízos de valor ficaram suspensos. Desejou-se apenas retratar a vida onde ela estava: nas pessoas, nas vibrações e nos encontros produzidos, buscando tensionar as cristalizações do pensamento e experimentando as sensações. Nos encontros com os caminhantes foram construídas reflexões em conjunto com o campo e não sobre o campo pesquisado, por isso a todo o momento procurava-se questionar, indagar e perguntar durante os encontros a fim de movimentar o pensamento. Encontros e caminhadas pensadas para escapar às categorias identitárias, onde as singularidades pudessem emergir, pensando no múltiplo e não no indivíduo. E nessa multiplicidade experimentar o novo.

Os percursos realizados foram passeios em que identificava-se um começo, mas não as paradas, pois sem prever onde seriam as paradas. Os acontecimentos, o trajeto que seria percorrido, o local onde a caminhada seria concluída, nada era estabelecido a priori, mas ocorreu na ordem do "deixar levar". Com uma atenção difusa, sem roteiro pré-estabelecido, buscou-se permear ambientes habitados por corpos surdos com o intuito de acompanhar os processos e as experiências que realizavam, sem deter-se a nenhum produto final, apenas a atenção aberta aos acontecimentos, uma concentração sem foco, acolhendo o inesperado. 
Assim, as experiências foram acontecendo, de maneira fragmentada, de modo que, muitas vezes, não produziam um sentido imediato.

Como cartofotógrafa procurou-se não coletar dados, mas produzi-los. Não julgar, mas colocar em questão as forças que durante a caminhada, permearam. Pretendia-se produzir dados que possibilitassem fazer leituras das subjetividades, duvidando e questionando verdades manifestadas pelos corpos surdos, como por exemplo a colocação da caminhante B, quando ao entrar na cozinha de sua casa exclamou: "Aqui não, é tudo muito velho". Neste momento, questionamentos sobre belo se fizeram presentes, em detrimento de um ambiente de experimentações e provocações.

O papel da pesquisadora não foi oculto, mas conhecido pelos participantes, com os quais foi mantido diálogo, informando-os da intenção deste estudo através do Termo de Consentimento livre e esclarecido que receberam, visando, assim, um cuidado ético.

Para inventar travessias, os sentidos foram explorados, tatearam, rastrearam o campo, acompanhando mudanças de posição, de ritmo, de velocidade. As caminhadas não foram préestabelecidas e, especialmente na última caminhada realizada, sentia-se com mais vigor estes movimentos, pois a cada esquina do centro da cidade, por onde parava-se, escolhia-se para onde seguir. Neste sentido, cartografia e corpo tornam-se dependentes.

Em cada criação da obra Caminhando, de Clark, as singularidades vão se fazendo presentes. Tal tentativa se buscava também nesta dissertação, tornar presente as singularidades dos corpos surdos. Conhecia-se algumas cicatrizes já marcadas nestes corpos, mas buscava-se produzir fissuras nelas, uma vez que a vida é um processo e a criação é um ato, lembrando que tudo o que produzimos nasce de um ato imanente, de um encontro. No entanto, as linhas duras pareciam não se desprender dos encontros, pois com as três caminhantes elas se fizeram presentes, principalmente nos diálogos, os quais sempre giravam em torno de trabalho, estudo e salário. Tais pontos mostravam o quão desafiador é tentar fazer alguns rasgões nos mesmos e entregar-se aos instantes momentâneos da vida.

No decorrer dos encontros, quando os caminhantes eram fisgados pelos punctuns que os afetavam, percebia-se neles uma mudança em suas expressões faciais, quando os olhos pareciam brilhar mais e um sorriso estampava suas faces, especialmente no segundo encontro, em que uma das caminhantes fotografou o quadro na sala de casa, chegando a suspirar quando fixou os olhos sobre ela. Ainda no encontro com a caminhante B percebe-se uma constante referência ao filho, que ficou estampada nas fotografias. Neste momento é possível lembrar 
das construções de Barthes (1984) em torno da morte da fotografia, da morte do instante, uma vez que a medida que o filho for crescendo, as fotografias ficarão registradas como lembrança, como passado.

Com relação às caminhantes $\mathrm{A}$ e $\mathrm{C}$ percebe-se que os punctuns encontravam-se na natureza, pois as mesmas registraram árvores, plantas e flores. Assim, a carto(foto)grafia teve o intuito de deixar levar pelos acontecimentos, experienciando os momentos que foram vividos. Experimentando da mesma forma que a borboleta que voa e, ao encontrar um lugar que a fisga, paira e o sente. As caminhadas ocorreram sem um local determinado, com possibilidades de atentar ao despercebido, acompanhando os processos, possibilidades de escapes do corpo, alternativas para perceber o quanto o corpo encontra brechas na vida, de forma a afirmar suas singularidades, sem visar um plano comum entre os heterogêneos.

\section{DA SUSPEITA CHEGADA}

Com as fotografias e diário de campo nas mãos, encontra-se uma encruzilhada. O que fazer? Ir por este caminho, por aquele, por uma terceira via? Regressar? Escolhe-se um: o caminho dos encontros, ou melhor, o caminho dos desencontros. Ao colocar os pés nele, o corpo cria uma expectativa. Não esperava-se encontros com roteiros e personagens definidos por um script, mas uma expectativa que relacionava-se com algo incomum, que provocasse movimento, entrelaçamentos, vibrações e singularidades. Talvez neste detalhe, sem desejar, morava um sutil engano.

Os corpos mostravam-se singulares, em certos momentos, e corriqueiros, identitários em outros. Assim, percebe-se que a pesquisa poderia dizer de um corpo apenas, não um corpo surdo, tão somente. Neste momento, as palavras de Rolnik (2006, p. 13), são lembradas: “o que encontramos, aqui, é um corpo que se abre às forças da vida que agitam a matéria do mundo e as absorve como sensações, a fim de que estas por sua vez nutram e redesenhem sua tessitura própria".

Algumas vezes, ao deparar-se com as fotografias surgiam questionamentos: Mas o que há nelas? Era necessário um corpo surdo para registrá-las? Fotografias coladas à vida cotidiana, a uma vida banalizada. Em outros momentos, a expectativa do surpreendente também tomava força no corpo, mas o que encontra-se? Um registro comum, corriqueiro, tanto nos fotográficos quanto nos assuntos que atravessavam os encontros. Diálogos que ao serem tensionados, corroboravam com temas comuns entre a maioria dos sujeitos que 
trabalham, tem filhos e compromissos. No entanto, em alguns momentos, tenta-se negar, não dar ouvidos aos assuntos que permeavam, mas eles estavam lá, insistindo em aparecer. Nesse sentido, aproximamo-nos das ideias de Barthes (1984, p. 114) quando diz que "portanto, a partir de então, eu devia aceitar misturar duas vozes: a da banalidade (dizer o que todo mundo vê e sabe) e a da singularidade (salvar essa banalidade de todo o ardor de uma emoção que só pertencia a mim".

Uma ideia de criação, de invenção do pensar o impensado também acompanhava o percurso com os caminhantes, mas esta ideia não se confirmava e durante cada encontro algumas situações se repetiam, de outros modos, mas sobre os mesmos pontos, como por exemplo, a visibilidade que foi dada à natureza. Novamente o questionamento: Apenas um corpo surdo poderia perceber a natureza?

Ao sair com os caminhantes, imaginava-se que os mesmos fotografariam pequenos detalhes e sobre eles fariam uma relação com palavras que emanariam sonoridade e poesia, usariam, talvez, expressões, com rimas e frases sensíveis como a brisa que toca o rosto em uma noite de lua cheia, por onde cantam bem-te-vis que sobrevoam no céu estrelado, batendo livremente suas vibrantes asas.

Os princípios da cartografia são rememorados: nada traça antes do acontecimento, nem expectativas, nem roteiros, mas sim pistas. No entanto, algo emerge: os encontros eram permeados por objetividade. Objetividade e brevidade, em detrimento da entrega que esperava-se. Objetividade que apareceu na fotografia dos manequins de vitrines de lojas quando caminhava-se pelo centro da cidade. Não está se estudando corpo? Então, para os caminhantes, a fotografia dos manequins era perfeita. E revela-se aqui que não foi apenas uma fotografia de manequins registrada, mas em torno de três, todas com o mesmo propósito: o corpo. É corpo, sempre na tentativa de mostrar o que é, suas formas, seus atributos.

Manequim criança, manequim homem, manequim mulher. Manequim igual a corpo. Corpo enquanto representação, embora nos diálogos, na tentativa de tentar provocar o pensamento dos caminhantes, buscava-se explicar que não estava estudando um corpo enquanto cabeça, braços e pernas, mas um corpo das sensações, um corpo que se deixa afetar. E novamente buscava-se encontrar singularidades nos corpos surdos, mas os corpos surdos apenas afirmavam a identidade de um corpo, suas representações e formas.

Segue-se pensando que a pesquisa poderia tratar de um corpo apenas. Um corpo enquanto fora, enquanto sensível, que fotografa o que lhe afeta, o que lhe desacomoda, 
desassossega, provoca, incomoda, desestabiliza, ou simplesmente fotografa o que vê e sente, seja por, conforme Barthes (1984, p. 35 e 36),

\begin{abstract}
desejar o objeto, a paisagem, o corpo que ela representa; seja amar ou ter amado o ser que ela nos dá a reconhecer; seja espantarmo-nos com o que vemos; seja admirar ou discutir o desempenho do fotógrafo, etc.; mas esses interesses são frouxos, heterogêneos; tal foto pode satisfazer a um deles e me interessar pouco; e se tal outra me interessa muito, eu gostaria de saber o que, nessa foto, me dá o estalo. Assim, parecia-me que a palavra mais adequada para designar (provisoriamente) a atração que sobre mim exercem certas fotos era aventura. Tal foto me advém, tal outra não.
\end{abstract}

Um corpo qualquer, que não fosse este, nem aquele, mas que fotografa e esboça traços de uma aquarela de forças que da vida emanam, tentando borrar a timidez de um fim de tarde. Um corpo que se compõe nas tramas da vida, dos momentos, das experimentações, despreocupado com as comprovações, das quais Barthes (1984) procurou tranquilidade em detrimento de um viver singular e íntimo. Talvez também um corpo que deseja a morte da fotografia, como uma representação permanente da vida. Uma fotografia que guarde lembrança, que guarde algo daquele momento que não mais retornará.

No entanto, uma pesquisa é feita de escolhas. É do corpo surdo que escolhe-se tratar e com ele inventar trajetos em meio a caminhadas distraídas. Das lentes, ora emergia o mesmo, ora, mais raramente, alguma intensidade saltava. Da tentativa de inventar fluxos, parece que o pé voltava sempre ao chão, firme e fixo, colando uma forma à outra. E por estas linhas foi-se percebendo sons de tramas representativas perpassando às entranhas dos corpos.

Neste sentido, a pesquisa se delineou em meio a mapeamentos, tentando escapar às representações, às identidades. Percebe-se que a ideia de operar com a carto(foto)grafia movimentou sutilmente, os corpos surdos. Movimento que para os caminhantes não era costumeiro e por isso, um certo estranhamento à proposta foi visível durante os encontros. É fácil repetir o já feito, o já construído. Difícil é borrar fronteiras históricas e sociais, desviando-as, torcendo-as.

A intenção de caminhar mostrou muitos passos tortuosos, que lidavam com erros, acertos, tentativas, variações. Inusitados. Acontecimentos. Paradas. Carto(foto)grafias. Experienciar a caminhada pelas lentes da câmera, que registra o que afeta. Seria este o propósito? O objetivo? Uma pista: "O corpo disforme do tocador de sinos possuía a aparência de um monstro porque podia assumir mil formas" (SERRES, 2004, p. 80). Assim como Serres (2004) descreve, buscou-se vivenciar os espaços por onde se passava, talvez pensando o corpo enquanto tocador de sino, que deforma-se, na medida em que é contaminada pelas sensações 
que registra. Lispector (1999, p. 81) afirma:

Meu corpo estava fora de mim e eu o vi transparente e através da transparência artérias pulsantes, vivas, plenas de sangue que circulava com a mais alta velocidade possível por todos os membros: pareciam canais de irrigação. Vi também ar, água e um líquido amarelo. Via tudo em cores.

Passagens, andares, trocas. Agora o final, o ponto. A vida que pulsava em cada encontro, neste momento instaura-se no corpo como lembranças, experiências vividas, passadas. No pensamento algo a provocar: de agora em diante, para onde escapar?

\title{
CUERPO SORDO Y SUS SINGULARIDADES
}

\section{Resumen}

El presente artículo se refiere a un recorte de disertación de máster realizado en el Centro Universitário Univates en el período de julio de 2013 a julio de 2015. En medio a teorizaciones de filósofos de la diferencia, entre ellos Deleuze y Barthes, se toma el siguiente problema de investigación: ¿Cómo un cuerpo sordo sufre estimulación por otras vías que no la representación? Tal problema se desdobla en los siguientes objetivos: comprender los modos por los cuales algunos cuerpos sordos se singularizan y cómo potencializan su vida; Carto(foto)grafía los afectos producidos por el cuerpo sordo en encuentros con la fotografía. Estas carto(foto)grafias fueron realizadas en momentos distintos, con tres sujetos sordos en las ciudades de Lajeado/RS y Estrela/RS, partiendo de trayectos recurridos con el uso de la cámara fotográfica. El encuentro con la obra "Caminando", de Lygia Clark (1964) sirvió para que el recorrido fuese pensado mientras la obra se realiza en el acto. Por veces, un cuerpo inacabado, en movimiento de constante rechazo a la fijación. En muchas otras, sólo un cuerpo capturado por líneas estratificadas. Al finalizar la investigación, se percibió que la entrega del cuerpo es siempre algo difícil, de modo que se fija más en la objetividad y brevedad, de aquello que un cuerpo es capaz de producir mientras sea singular.

Palabras clave: Cuerpo Sordo; Punctum; Carto(foto)grafía

\section{THE DEAF BODY AND ITS SINGULARITIES}

\author{
Abstract


This article refers to a section of a master dissertation held at Univates University Center from July 2013 to July 2015. Among the theories of philosophers of difference, including Deleuze and Barthes, the following research problem was taken: How a deaf body is pierced by different means other than the representation? Such a problem unfolds on the following objectives: understanding the ways in which some deaf bodies are unique and how they empower their lives; carto(photo)graphing the affects produced by the encounter between a deaf body and the photography. These carto(photo)graphs were held at different times, with three deaf people in the cities of Lajeado / RS and Estrela / RS, from paths which were traveled using a camera. The encounter with the work "Walking" by Lygia Clark (1964) served to think the route as a work that takes place in the act. In some cases, an unfinished body in motion of constant refusal to fix; in many others, only one body captured by stratified lines. At the end of the survey, it's possible to see that the body's release is always difficult, so that it is more fixed in the objectivity and brevity, rather than in what a body is capable of producing as uniqueness.

Keywords: Deaf Body; Punctum; Carto(photo)graph

\section{REFERÊNCIAS}

BARTHES, Roland. Câmara Clara: nota sobre a fotografia. Rio de Janeiro: Nova Fronteira, 1984.

CLARK, Lygia. Da supressão do objeto (anotações) [1975]. In: FERREIRA, Glória;

COTRIM, Cecília (Orgs.). Escritos de artistas: anos 60/70. Rio de Janeiro: Zahar, 2013.

. Caminhando. Livro-obra. Disponível em: <www.lygiaclark.org.br/arquivoPT.asp $>$. Acesso em: 28 jan. 2015.

COSTA, Luciano Bedin da. Cartografia: uma outra forma de pesquisar (material pedagógico não publicado). Setrem - Faculdade Três de Maio, 2009.

DELEUZE, Gilles. Diferença e repetição. Tradução Luiz Orlandi, Roberto Machado. Rio de Janeiro: Graal, 2006.

GESSER, Audrei. LIBRAS? Que língua é essa?: crenças e preconceitos em torno da língua de sinais e da realidade surda. São Paulo: Parábola Editorial, 2009. 
KASTRUP, Virgínia. O funcionamento da atenção no trabalho do cartógrafo. In: ESCÓSSIA, Liliana da.; KASTRUP, Virgínia; PASSOS, Eduardo (Org.). Pistas do método da cartografia: Pesquisa-intervenção e produção de subjetividade. Porto Alegre: Sulina, 2009.

LANNA Júnior, Mário Cléber Martins (Comp.). História do Movimento Político das Pessoas com Deficiência no Brasil. Brasília: Secretaria de Direitos Humanos. Secretaria Nacional de Promoção dos Direitos da Pessoa com Deficiência, 2010. 443p: il. $28 X 24$ cm.

LISPECTOR, Clarice. Um sopro de vida. Rio de Janeiro: Rocco, 1999.

LOPES, Maura Corcini. Inclusão como prática política de governamentalidade. In: LOPES, Maura Corcini; HATTGE, Morgana Domênica (Org.). Inclusão escolar: conjunto de práticas que governam. Belo Horizonte: Autêntica Editora, 2009.

. A natureza educável do surdo: a normalização surda no espaço da escola de surdos. In: THOMA, Adriana da Silva; LOPES, Maura Corcini (Org.). A invenção da surdez I: cultura, alteridade, identidades e diferença no campo da educação. Santa Cruz do Sul: EDUNISC, 2004.

LUNARDI, Márcia Lise. EDUCAÇÃO ESPECIAL: institucionalização de uma racionalidade científica. In: THOMA, Adriana da Silva; LOPES, Maura Corcini (Org.). A invenção da surdez I: cultura, alteridade, identidades e diferença no campo da educação. Santa Cruz do Sul: EDUNISC, 2004.

MACHADO, Roberto. Deleuze, a arte e a filosofia. Rio de Janeiro: ZAHAR, 2013.

PEREIRA, Michele Quinhones; MAROSTEGA, Vera Lucia. Perspectivas pedagógicas na escola de surdos de Santa Maria. Revista Cadernos Educação Especial, Santa Maria: UFSM, n. 20, 2002. Disponível em: <http://coralx.ufsm.br/revce/ceesp/2002/02/a3.htm>. Acesso em: 22 dez. 2014.

ROLNIK, Suely. Uma terapêutica para tempos desprovidos de poesia. In: Lygia Clark. Da obra ao acontecimento. Somos o molde. A você cabe o sopro (Catálogo da exposição). Nantes/São Paulo: Musée des Beaux-Arts e Pinacoteca do Estado, 2006.

SCHÖPKE, Regina. Por uma filosofia da diferença: Gilles Deleuze, o pensador nômade. Rio de Janeiro: Contraponto, 2012.

SERRES, Michel. Variações sobre o corpo. Rio de Janeiro: Bertrand Brasil, 2004.

THOMA, Adriana da Silva. Educação dos surdos: dos espaços e tempos de reclusão aos espaços e tempos inclusivos. In: THOMA, Adriana da Silva; LOPES, Maura Corcini (Org.). A invenção da surdez II: espaços e tempos de aprendizagem na educação de surdos. Santa Cruz do Sul: EDUNISC, 2006.

ZOURABICHVILI, François. O vocabulário de Deleuze. Tradução de André Telles. Rio de Janeiro: Ed. Relume Dumará, 2004. 
RODRIGUES, A.; MUNHOZ, A.V.; HATTGE, M. D.

Data de aceite: 27/10/2015

Revista Reflexão e Ação, Santa Cruz do Sul, v. 23, n. 3, p. 104-124, Set./Dez. 2015. http://online.unisc.br/seer/index.php/reflex/index 